\title{
Influence of sandblasting of zirconia veneered with Zirox on bond strength and static fatigue behaviour by Schwickerath-Test
}

\author{
Ch. Schille, K. Wieland, J. Geis-Gerstorfer \\ Dental Clinic, Section Medical Materials \& Technology, University Hospital Tübingen, Germany, \\ e-Mail: Christine.Schille@med.uni-tuebingen.de
}

\begin{abstract}
There are different recommendations for sandblasting of zirconia. The aim of this study was to compare the influence of sandblasted zirconia veneered with Zirox on bond strength and static fatigue. 120 stripes of zirconia were prepared, 60 samples were sandblasted with $110 \mu \mathrm{m} \mathrm{Al}_{2} \mathrm{O}_{3}$. For each test 30 samples were used of each group. The bond strength test was done according to ISO 9693. The fatigue behaviour was investigated using a static staircase test. The bond strength results according to ISO 9693 were not significantly different for both groups, however, the static fatigue test of sandblasted zirconia revealed higher bond strength values.
\end{abstract}

\section{Introduction}

For over 10 years zirconia is used as a restorative material in dentistry for crowns and bridges. An unsolved problem is chipping. A main characteristic of zirconia is the transformation from monoclinic to tetragonal phase and cubic phase. During surface treatment like sandblasting a change from tetragonal to monoclinic phase is possible which cause a volume increase. This phase transformation can cause a change of the thermal expansion coefficient value from $7.5 \times 10^{-6} / \mathrm{K}$ to $10.8 \times 10^{-6} / \mathrm{K}$ which has an influence on the bond strength [6]. To avoid chipping of the veneered porcelain some manufacturers recommend a healing firing of the zirconia substrate after sandblasting, others recommend no sandblasting [3, 4, 6-9].

Normally a good bond strength is given if the coefficient of thermal expansion of the veneered porcelain is smaller than of zirconia substrate in order to get compressive strain in the porcelain during the sintering and cooling process. Thus, it is important that the preparation steps of the bonding are done according to manufacturer`s instructions. The crack initation test according to Schwickerath, which is performed by 3-point-bending, is a standardized method to characterize the bond strength of metal-ceramic systems. According to ISO 9693 the bond strength can be calculated in two ways: (a) the bond strength is calculated according to $\sigma_{\mathrm{B}}=\mathrm{k} \cdot \mathrm{F}_{\text {fail }}$ with $\mathrm{k}$ as a correction factor depending on the Young's modulus and thickness of the substrate and $F_{\text {fail }}$ repesenting the maximum load of the veneered ceramic until fracture or, (b) the bond strength can be calculated from a special diagram according to Lenz which include the thickness of metal and different young's moduli of the substrate from which $\mathrm{k}$ can be taken. According to ISO 9693 with both calculation modes the bond strength must be more than $25 \mathrm{MPa}$ for metal-ceramic systems [1, 5].

In this study Zenotec $\mathrm{Zr}$ (Wieland Dental + Technik \& Co. $\mathrm{KG}$, Pforzheim) as zirconia substrate $\left(95 \% \mathrm{ZrO}_{2}, 4 \% \mathrm{Y}_{2} \mathrm{O}_{3}\right.$, $\mathrm{Al}_{2} \mathrm{O}_{3}<1 \%$ ) and Zirox (a one-phase silicat glass ceramics without Leucite) as a veneering porcelain was used. The coefficient of thermal expansion of Zenotec $\mathrm{Zr}$ is given with $10.5 \times 10^{-6} / \mathrm{K}$ and $9.3 \times 10^{-6} / \mathrm{K}$ for Zirox by the manufacturer. The bonding between zirconia substrate and
Zirox is mechanically and chemically: According to the instructions of the manufacturer the surface treatment of zirconia substrate is treated with instruments under low pressure and cooling with water. For surface finishing and cleaning the zirconia substrate is sandblasted with 110-150 $\mu \mathrm{m} \mathrm{Al}_{2} \mathrm{O}_{3}$ at 2 bar and cleaned with water. Then a thin layer of liner is put on the substrate.

For the moment there exist no standardized method for testing zirconia in terms of bond strength and fatigue. The aim of the study was to investigate the influence of sandblasting of zirconia substrate veneered with porcelain on the bond strength and static fatigue behaviour by Schwickerath-Test according to ISO 9693.

\section{Methods}

\subsection{Preparation of samples}

120 stripes of zirconia (Zenotec $\mathrm{Zr}, 25 \times 4 \times 0.8 \mathrm{~mm}$ ) were fabricated by $\mathrm{CAD} / \mathrm{CAM}$ technique. 60 samples were sandblasted on one side with $110 \mu \mathrm{m} \mathrm{Al}_{2} \mathrm{O}_{3}$ with a pressure of 2 bar and a distance of $5 \mathrm{~cm}$ of the sandblasting pen to the sample. In the middle of each stripe the veneering porcelain Zirox was applied over an area of $8 \times 4 \times 1 \mathrm{~mm}$ with different firings (liner, opaque, Dentin 1 and 2 according to the manufacturer's instructions) using a special sample holder. All firings were done with a Multimat Touch (Dentsply). The firing profiles can be seen in Table 1.

Table 1: firing profiles

\begin{tabular}{|c|c|c|c|c|}
\hline & 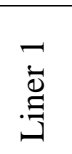 & こ & 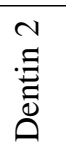 & $\begin{array}{l}\stackrel{0}{\Xi} \\
\stackrel{\mathbb{N}}{ত}\end{array}$ \\
\hline Starting temperature $\left[{ }^{\circ} \mathrm{C}\right]$ & 575 & 575 & 575 & 575 \\
\hline Drying time [min.] & 8 & 9 & 8 & 5 \\
\hline Heating rate $\left[{ }^{\circ} \mathrm{C} / \mathrm{min}.\right]$ & 45 & 45 & 45 & 45 \\
\hline Firing temperature $\left[{ }^{\circ} \mathrm{C}\right]$ & 930 & 900 & 890 & 880 \\
\hline Firing time [min.] & 1 & 2 & 1 & $1-2$ \\
\hline Time with Vacuum [min.] & 1 & 1 & 1 & 1 \\
\hline Vacuum $[\mathrm{hPa}]$ & 50 & 50 & 50 & - \\
\hline
\end{tabular}


From each group 30 samples were used for bond strength test and 30 samples for the static fatigue test.

\subsection{Bond strength test according to ISO 9693}

The bond strength test was performed according to ISO 9693. With each sample a 3-point-bending test was done with a Universal testing machine (Zwick Z010, Software: test expert Vers. 12, Zwick, Ulm) and a crosshead speed of $0.5 \mathrm{~mm} / \mathrm{min}$. In the bottom of the 3-point-bending test device a microphone was mounted which was connected to the Universal testing machine. With each specimen a F-d-Diagram together with the acoustic signal was recorded and the parameters according to table 2 were calculated. Image 1 represent a typical measurement plot with all the calculated parameters. The results of them can be seen in table 2 .
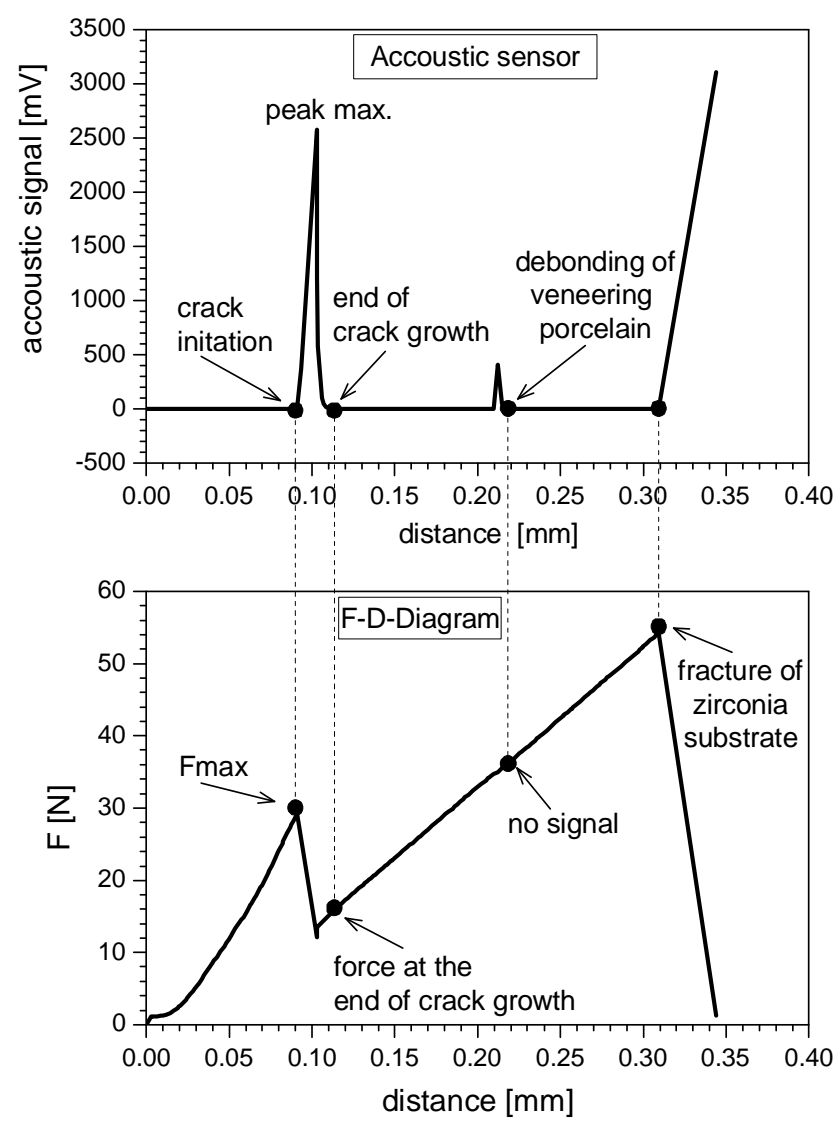

Image 1: Example of a measurement plot from bond strength test according to ISO 9693.

For the calculation of the bond strength the equation (a) was used. For the determination of the time for crack growth the difference of the distance between the end of crack growth and and crack initation was calculated using the equation $t=d / v$ with $v$ as the crosshead speed. In a similar way the time until debonding of the veneered porcelain was calculated.

\subsection{Static Fatigue Test}

Before starting the staircase test each sample was stored in water for 48 hours. The 3-point-bending test device was put into a water bath and the specimen was covered with water. For the static fatigue test a staircase test was performed with a crosshead speed of $0.5 \mathrm{~mm} / \mathrm{min}$. starting from $5 \mathrm{~N}$ with a holding time of $4 \mathrm{~h}$ at every step and a step increase of $5 \mathrm{~N}$. These steps were repeated until debonding of the veneered porcelain from zirconia substrate appeared. From each measurement a F-t-Diagram together with a d-t-Diagram was recorded. An example of a measurement plot with all the calculated parameters can be seen in image 2.

\section{Results}

The calculated parameters of all tests which were done in this study can be seen in Tab. 2 and Tab. 3 .

\subsection{Results of bond strength test according to ISO 9693}

Table 2: Calculated parameters of bond strength test

\begin{tabular}{|l|c|c|}
\hline \multicolumn{1}{|c|}{ Parameter } & $\begin{array}{c}\text { as machined } \\
(\mathrm{n}=29)\end{array}$ & $\begin{array}{c}\text { sandblasted } \\
(\mathrm{n}=28)\end{array}$ \\
\hline Fmax [N] & $28.59 \pm 5.52$ & $29.65 \pm 5.80$ \\
\hline Bond strength [MPa] & $\begin{array}{c}56.12 \pm \\
10.97\end{array}$ & $60.77 \pm 16.75$ \\
\hline Weibull modulos $\sigma_{\mathrm{m}}$ & 5.8237 & 4.5912 \\
\hline $\begin{array}{l}\text { Weibull strength } \sigma_{0} \\
{[\mathrm{MPa}]}\end{array}$ & 4.1044 & 4.1997 \\
\hline $\begin{array}{l}\text { Microphone signal } \\
\text { Peak max [mV] }\end{array}$ & $\begin{array}{c}3184.05 \pm \\
562.56\end{array}$ & $\begin{array}{c}2789.08 \pm \\
669.40\end{array}$ \\
\hline Time of crack growth [s] & $2.64 \pm 0.41$ & $2.84 \pm 0.38$ \\
\hline $\begin{array}{l}\text { Time [s] until debonding } \\
\text { of the veneered porcelain } \\
\text { from substrate }\end{array}$ & $30.08 \pm 4.66$ & $29.80 \pm 2.97$ \\
\hline $\begin{array}{l}\text { Force [N] at the end of } \\
\text { crack growth }\end{array}$ & $13.88 \pm 3.38$ & $13.90 \pm 2.87$ \\
\hline $\begin{array}{l}\text { Calculated strength } \\
{[\text { MPa] at the end of crack }} \\
\text { growth }\end{array}$ & $29.35 \pm 4.72$ & $31.26 \pm 7.18$ \\
\hline
\end{tabular}

The results of bond strength test showed that all calculated values are very similar. All calculated parameters were not significantly different between both groups. 


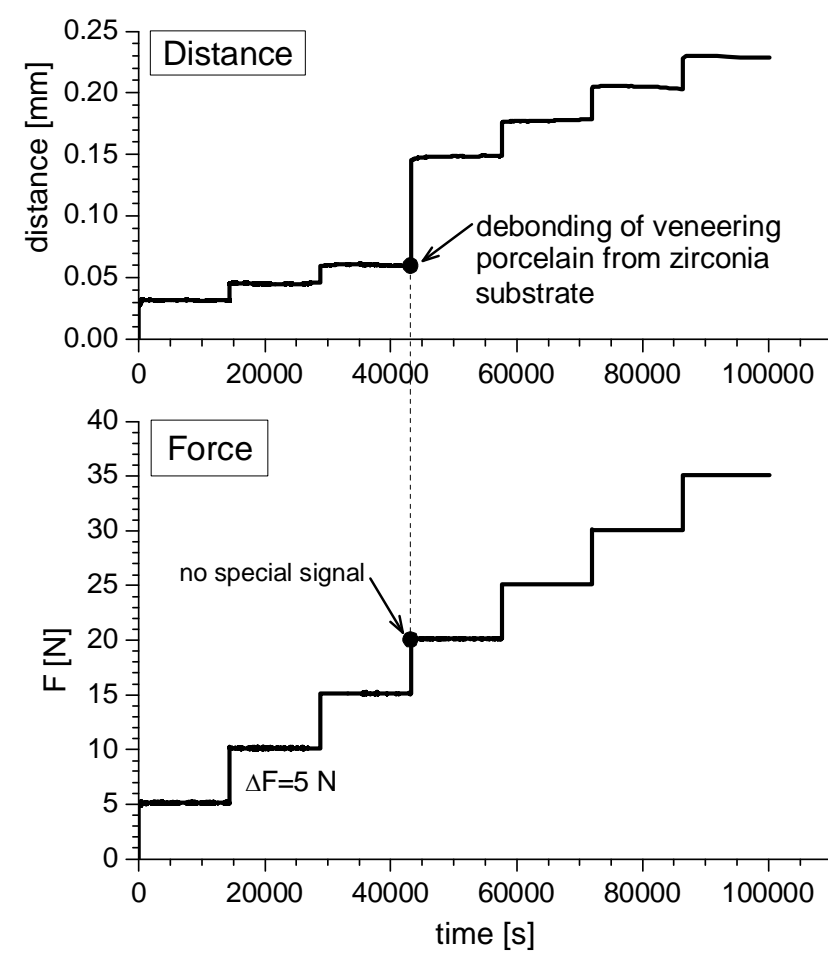

Image 2: Example of a measurement plot from static fatigue test

From all samples the crack initation started at Fmax of veneered porcelain. At the end of crack growth the force is reduced to the half. Student's T-test $(\mathrm{p}<0.05)$, which was applied with all calculated parameters from bond strength test, showed significant differences only with the Peak maximum values of the microphone signal.

\subsection{Results of static staircase test}

The calculated results can be seen in Table 3 .

Table 3: Calculated parameters of static fatigue test

\begin{tabular}{|l|c|c|}
\hline \multicolumn{1}{|c|}{ Parameter } & $\begin{array}{c}\text { as machined } \\
(\mathrm{n}=29)\end{array}$ & $\begin{array}{c}\text { sandblasted } \\
(\mathrm{n}=30)\end{array}$ \\
\hline Force step of fracture [N] & $18.93 \pm 19.25$ & $21.90 \pm 21.79$ \\
\hline Force reduction [\%] & $33.79 \pm 32.67$ & $26.14 \pm 23.78$ \\
\hline Remaining time [h] & $15.95 \pm 5.47$ & $15.37 \pm 6.02$ \\
\hline Strength [MPa] & $38.64 \pm 39.30$ & $44.71 \pm 44.48$ \\
\hline Strength reduction [\%] & $31.14 \pm 29.97$ & $26.42 \pm 26.81$ \\
\hline
\end{tabular}

Table 4: Number of fracture event at each step of force

\begin{tabular}{|c|c|c|}
\hline step of Force $[\mathrm{N}]$ & as machined & sandblasted \\
\hline $5-10$ & 0 & 0 \\
\hline $10-15$ & 6 & 9 \\
\hline $15-20$ & 6 & 5 \\
\hline $20-25$ & 4 & 2 \\
\hline $25-30$ & 9 & 11 \\
\hline $30-35$ & 4 & 3 \\
\hline
\end{tabular}

The results from staircase test showed a high standardiviation for both groups. Because the fracture occurred in different force of steps, the number of the fracture event at each step of force and for the remaining time at each step of holding time are listed in table 4 and 5.

Table 5: Number of removal events at each step of force

\begin{tabular}{|c|c|c|}
\hline holding time $[\mathrm{h}]$ & as machined & sandblasted \\
\hline $0-4$ & 0 & 0 \\
\hline $4-8$ & 3 & 5 \\
\hline $8-12$ & 8 & 8 \\
\hline $12-16$ & 5 & 2 \\
\hline $16-20$ & 6 & 4 \\
\hline $20-24$ & 7 & 9 \\
\hline $24-28$ & - & 2 \\
\hline
\end{tabular}

\section{Conclusions}

\subsection{Bond strength test according to ISO 9693}

With the acoustic sensor it is possible to include more parameters like the debondig time of veneered porcelain and the time of crack growth. Thus, in addition to the bond strength information about of the remaining time of the veneered porcelain on the substrate is given.

The acoustic sensor signal is useful to check if the crack intitation is corresponding to Fmax or not. This was different 4 times for the as machined and 3 times for the sandblasted zirconia samples.

To use the Schwickerath crack initiation test for the bond strength of dental ceramics and veneered porcelain, the diagram from ISO standard had to be adjusted to other thickness values and elastic modulus of ceramic substrates. The calculated bond strength data of this study had to be calculated again with the new adjusted k-factor.

\subsection{Static Fatigue Test}

The calculations of the static fatigue test were only possible in combination with the distance-time diagrams.

\subsection{General}

Sandblasting of Zenotec veneered with Zirox can improve the fracture resistance. This could be seen with the calculated force reduction of Fmax from Schwickerath-Test compared to the force step of fracture from static staircase test.

\section{References}

[1] DIN EN ISO 9693: Dentale restaurative Metallkeramiksysteme. DIN-Taschenbuch 267:Zahnheilkunde. Beuth Verlag, 2010

[2] DIN EN ISO 6872: Zahnheilkunde - Keramische Werkstoffe. DIN-Taschenbuch 267:Zahnheilkunde. Beuth Verlag, 2010

[3] Fokas, G.: Influence of the surface and heat treatment on the flexural strength and reliability of Y-TZP dental ceramic. Med Diss Tübingen, 2010.

[4] Kern, M., Bauer, H.-G., Kimmich, H.: Das 1x1 der Zirkonoxid-Behandlung. Zahntech Mag 2010, 14, 1/2: 28-32 
[5] Schwarz, S., Lenz, J., Schwickerath, H: Zur Festigkeit des metallkeramischen Verbundes bei der Biegeprüfung. Dtsch Zahnärztl Z 1988, 43:1152-1158

[6] Tada, K., Sato, T., Yoshinari, M.: Influence of surface treatment on bond strength of veneering ceramics fused to zirconia. Dent Mater J 2012; 31(2): 287-296

[7] Wehnert, L., Radlanski, R.J., Freesmeyer, W.B. : Untersuchungen zum Verbund von Zirkonia TZP zu ausgewählten Verblendkeramiken. Quintessenz Zahntech 2010; 36(1):36-47.

[8] Wehnert, L., Slotosch, S., Fressmeyer, W.B.: Einfluss von mechanischen Oberflächenbearbeitungsverfahren auf den Verbund von Y-TZP zu vier Verblendkeramiken. Quintessenz Zahntech 2011; 37(3): 342-356.

[9] Yamaguchi, H., INO, S., Hamano, N., Okada, S., Teranaka, T.: Examination of bond strength and mechanical properties of Y-TZP zirconia ceramics with different surface modifications. Dent Mater J 2012; 31(3): 472-480.

\section{Acknowledgement}

The authors thank Wieland Dental + Technik GmbH \& Co. $\mathrm{KG}$ (Pforzheim) for supporting this study. 